\title{
Creep study on Alumina and Alumina/SWCNT nanocomposites
}

\author{
Miguel Castillo-Rodríguez ${ }^{1 *}$, Antonio Muñoz ${ }^{2}$ and Arturo Domínguez-Rodríguez ${ }^{2}$ \\ ${ }^{1}$ Instituto de Ciencia de Materiales de Sevilla, CSIC-Universidad de Sevilla, Avda. Américo \\ Vespucio 49, 41092 Sevilla, Spain \\ ${ }^{2}$ Departamento de Física de la Materia Condensada, Facultad de Física, Universidad de \\ Sevilla, Apartado 1065, 41080 Sevilla, Spain
}

\begin{abstract}
Alumina and alumina/SWCNT nanocomposites have been sintered by spark plasma sintering, obtaining relative densities higher than 99\%. Microstuctural characterization revealed a grain microstructure in the submicron range, where alumina/SWCNT nanocomposites exhibited a good CNTs dispersion thought the ceramic matrix. Creep experiments performed in both materials showed a similar mechanical behavior, where the addition of CNTs seems to have a negligible effect on the strain rate, in contrast to results reported by other authors. Grain boundary sliding accommodated by lattice diffusion has been identified as the high temperature deformation mechanisms in both samples, alumina and alumina/SWCNT nanocomposites. We have discussed about the role of CNTs influence on the plasticity of these composites.
\end{abstract}

Keywords: Nanotubes; Alumina; Composites; Creep; Mechanical properties;

*Corresponding author: miguelcr@us.es. Instituto de Ciencia de Materiales de Sevilla, CSICUniversidad de Sevilla, Avda. Américo Vespucio 49, 41092 Sevilla, Spain. Tel: Int-34-95 45509 64, Fax: Int-34-95 4612097.

\section{Introduction}


High-temperature strength, wear resistance and chemical stability of $\mathrm{Al}_{2} \mathrm{O}_{3}$ polycrystalline make this ceramic suitable for many applications in diverse fields such as, armour systems, wear resistance products, electronic substrates, cutting tools, automotive parts, components for power generator, turbine hot-section and aero-engine [1-4]. However, the low fracture toughness value of alumina limits its performance, as it occurs with all ceramic materials [5]. Since the discovery of carbon nanotubes (CNTs) with their remarkable strength and stiffness, chemical and thermal stability and excellent flexibility [6-8] has motivated extensive research activity in designing ceramic/CNT composites with improved fracture toughness and strength compared with monolithic ceramics.

Nonetheless, there is still a big controversy whether the incorporation of CNTs in a ceramic matrix produces a strengthening and toughening effect or not [9-16]. Furthermore, the technique used to measure the fracture toughness, Vickers indentation fracture (VIF) or single edge notched beam (SENB), seems to contribute to this controversy. Thus in $\mathrm{Al}_{2} \mathrm{O}_{3} / \mathrm{SWCNTs}$ composites, Vickers indentation gives higher fracture toughness values than those measured in fully dense pure $\mathrm{Al}_{2} \mathrm{O}_{3}[11,15]$, however no increase is found from SENB tests $[12,15]$.

Regarding the high temperature mechanical properties, the influence of the incorporation of CNTs on a ceramic matrix it is still unclear. Thus, in 3YTZP/CNTs ceramics some authors have reported that CNTs/ceramic composites exhibit a higher strength compared with monolithic ceramic [17], but conversely others found a clear softening effect and argued that CNTs makes grain boundary sliding easier during deformation instead of acting as a reinforcing element [18]. For CNTs/alumina composites, similar situation is found in the literature [19-31]. Zapata-Solvas et al. [19,20] studied the creep resistance in a 10 vol\% SWCNT-reinforced alumina composites deformed in compression and they found to be about two orders of magnitude more creep-resistant compared to pure alumina of the same grain size. The enhancement in the creep resistance was attributed to a grain boundary sliding reduction 
as a consequence of partially blocking of GBS due to CNTs presence at $\mathrm{Al}_{2} \mathrm{O}_{3}$ grain boundaries [19-21]. It is worth emphasizing that the reliability of these results is not clear since these authors compared their mechanical results of $\mathrm{SWCNT}-\mathrm{Al}_{2} \mathrm{O}_{3}$ nanocomposites with experimental data for pure alumina from the literature, where creep data exhibit a high dispersion depending on the microstructure and the presence of impurities [26,31].

However, this reinforcing effect seems not to be in agreement to what found by Estili et al. [22]. After deformation at $1400{ }^{\circ} \mathrm{C}$ with a strain rate of $10^{-4} \mathrm{~s}^{-1}$ of a fully dense $20 \mathrm{vol} \%$ surface acid-treated MWCNT- $\mathrm{Al}_{2} \mathrm{O}_{3}$ matrix hybrid and monolithic $\alpha-\mathrm{Al}_{2} \mathrm{O}_{3}$ with initial grain size of 150-350 nm, they observed a much lower flow stress in the composites (40 MPa) than in pure alumina (110 MPa). This softening effect was also observed by Huang et al. [23] by the addition of $0.5 \mathrm{wt} \%$ of $\mathrm{BN}$ nanotubes to an alumina matrix.

The creep behaviour of $\mathrm{Al}_{2} \mathrm{O}_{3}$ has been studied more extensively than any other crystalline solid [24-26]. Usually, the creep results are analysed using the standard phenomenological creep equation:

$$
\dot{\varepsilon}=A \frac{G b}{K T}\left(\frac{b}{d}\right)^{p}\left(\frac{\sigma}{G}\right)^{n} \mathrm{D}
$$

where

$$
D=D_{0} \exp \left(-\frac{Q}{R T}\right)
$$

being $A$ a constant, $G$ the shear modulus, $b$ the magnitude of the Burgers vector, $\sigma$ the applied stress, $d$ the grain size, $K$ the Boltzmann's constant and $T$ the absolute temperature, $R$ the gas constant, D the diffusion coefficient and $D_{0}$ a frequency factor. The parameters $\mathrm{n}, \mathrm{p}$, and $\mathrm{Q}$ (generically known as creep parameters) are, respectively, the stress and grain size exponents, and the apparent activation energy for creep. 
Grain boundary sliding (GBS) is the commonly accepted dominant deformation mechanism in creep of fine-grained alumina materials. However, there are some discrepancies about the accommodation process. Some authors claim that GBS is accommodated by dislocation glide and climb [26]. However, to activate dislocations in alumina are necessary much higher stresses than that used in these creep experiments [27-29]. This is the reason why dislocation activity has been never observed in these experiments [27-29] and it has been discarded.

GBS accommodated by diffusional processes can explain successfully the plasticity of alumina and other ceramics like yttria-zirconia system without the concurrence of dislocations [30]. For alumina there is an extra issue which is related to the high diffusion coefficient dispersion values. High temperature mechanical behaviour is controlled by diffusion in alumina, so creep rates are determined by the motion of the slower specie ( $\mathrm{Al}$ or $\mathrm{O}$ ) [see eq. 1 and 2]. Diffusion coefficient depends strongly on the microstructure and it is highly sensitive to the presence of impurities [31]. This fact makes very risky to establish direct comparison between experimental data from samples sintered under different conditions.

In this work we have sintered $2.5 \mathrm{vol} \% \mathrm{SWCNT}-\mathrm{Al}_{2} \mathrm{O}_{3}$ in order to investigate the influence of CNTs on the high temperature mechanical behaviour. For the sake of comparison, pure alumina has been also fabricated using the same sintering conditions. Creep experiments at temperatures between 1200 and $1250^{\circ} \mathrm{C}$ have been conducted in all fabricated specimens. Mechanical results have been analysed and compared.

\section{Experimental Procedure}

Commercially available $\alpha-\mathrm{Al}_{2} \mathrm{O}_{3}$ powder (Nanostructured and Amorphous Materials Inc., Houston, TX), with 30-40 nm average particle size and 99\% purity, was annealed in air at 1100 ${ }^{\circ} \mathrm{C}$ for one hour to remove the sintering additives from the starting powder and subsequently ball milled for 3 hours with a frequency of 25 vibrations/s (Model MM200, Retsch GmbH, 
Haan, Germany) to remove possible starting powder agglomerates generated during the previous annealing.

Regarding CNTs, commercially available $90 \%$ purified SWCNTs, with a typical bundle length of $0.5-1.5 \mu \mathrm{m}$ and diameter between $4-5 \mathrm{~nm}$, were provided by Carbon Solutions Inc. (Riverside, CA). They were $\mathrm{COOH}$-functionalizated following the same procedure described in $[18]$

$\mathrm{Al}_{2} \mathrm{O}_{3}$ powders and $\mathrm{Al}_{2} \mathrm{O}_{3} / \mathrm{CNT}$ s composite powders were sintered by Spark Plasma Sintering (Model Dr Sinter 1050, Sumitomo Coal Mining Co. LTD, Tokyo, Japan) at $1300{ }^{\circ} \mathrm{C}$, with a constant uniaxial pressure of $75 \mathrm{MPa}$ for 5 min under vacuum $\left(\sim 10^{-2} \mathrm{mbar}\right)$. The heating and cooling rates were $300{ }^{\circ} \mathrm{C} / \mathrm{min}$ and $50{ }^{\circ} \mathrm{C} / \mathrm{min}$, respectively. Densities of the sintered specimens were measured by Archimedes' method taking a density value of $1.3 \mathrm{~g} / \mathrm{cm}^{3}$ for SWCNTs, as it was given by the providers. As shown in Table I, relative densities higher than $99 \%$ were obtained.

The microstructure of the samples (as-sintered and after creep test) was examined by light microscopy (Model Leica DMRE, Leica Microsystems GmbH, Germany) and by high resolution scanning electron microscopy HRSEM (Model HITACHI S5200, Hitachi HighTechnologies Corporation, Tokyo, Japan) operating at 5kV. Prior to observation, sample preparation consisted on grounding and polishing with diamond paste of grain sizes down to $1 \mu \mathrm{m}$. Then, they were thermally etched in Ar atmosphere for $15 \mathrm{~min}$ at $1100{ }^{\circ} \mathrm{C}$ to reveal grain boundaries. $\mathrm{Al}_{2} \mathrm{O}_{3}$ grain morphology was studied by measuring the equivalent planar diameter $\mathrm{d}=(4 \times \text { area } / \pi)^{1 / 2}$ and the shape factor $\mathrm{F}=4 \pi \times$ area $/(\text { perimeter })^{2}$ from HRSEM micrographs on no less than 300 grains.

In $\mathrm{Al}_{2} \mathrm{O}_{3} / \mathrm{CNT}$ s composites, these same parameters were evaluated to characterize CNTs agglomerates along with the surface density, estimated from the area fraction covered by them 
in low magnification SEM micrographs and also by means of light microscope observations. Fracture cross-sections from composite specimens were also observed by HRSEM and investigated by Raman spectroscopy to study CNTs integrity after sintering and after creep tests, using a dispersive microscope (Model LabRAm Horiba Jobin Yvon, Horiba Ltd, Kyoto, Japan). Measurements were done with a green laser (He-Ne $532.14 \mathrm{~nm}), 20-\mathrm{mW}, 600 \mathrm{~g} / \mathrm{mm}$ grating and without filter. A $100 \times$ objective and a confocal pinhole of $100 \mu \mathrm{m}$ were used. The Raman spectrometer was calibrated using a silicon wafer.

The mechanical behaviour of the processed materials was investigated by uniaxial compression creep tests. Samples were cut and ground as parallelepipeds of approximate dimensions $5 \mathrm{~mm}$ $\times 2.5 \mathrm{~mm} \times 2.5 \mathrm{~mm}$. The creep tests were performed on a prototype creep machine [32] at temperatures between $1200{ }^{\circ} \mathrm{C}$ and $1250{ }^{\circ} \mathrm{C}$ and stresses ranging between 10 and $410 \mathrm{MPa}$ in a controlled argon atmosphere to avoid the combustion of SWCNTs. The creep curves were analysed using the standard phenomenological creep equation (Equation 1).

\section{Results and Discussion}

The microstructure of pure $\mathrm{Al}_{2} \mathrm{O}_{3}$ and SWCNT- $\mathrm{Al}_{2} \mathrm{O}_{3}$ nanocomposites before and after creep testing are shown in Fig. 1. Grains are faceted and some morphological parameter are shown in Table 1. Before creep tests, $\mathrm{Al}_{2} \mathrm{O}_{3}$ grains display an equivalent planar diameter $\mathrm{d}$ of $0.63 \pm$ 0.42 microns, whereas SWCNT- $\mathrm{Al}_{2} \mathrm{O}_{3}$ nanocomposites exhibit a smaller value $\mathrm{d}=0.36 \pm 0.17$ microns. It is clear that the addition of SWCNTs inhibits the ceramic grain growth during sintering, as reported by different authors $[33,34]$. Moreover, this grain growth inhibition effect is also observed during the compression creep tests because pure $\mathrm{Al}_{2} \mathrm{O}_{3}$ undergoes a slight grain growth after creep tests $(\mathrm{d}=0.78 \pm 0.48$ microns $)$ whereas the same equivalent planar diameter is obtained for SWCNT- $\mathrm{Al}_{2} \mathrm{O}_{3}$ nanocomposites after testing. We have obtained a similar shape 
factor close to 0.6 in all samples, indicating that there is no preferential grain growth direction and no microstructural evolution during the creep tests.

In case of nanocomposites, some black areas are observed at the grain boundaries. These black areas correspond to CNTs bundles and agglomerates. They have been more clearly observed in fracture surfaces (Fig 1.e) since the polishing process could modify the CNTs structure and appearance. Fig 1.e shows some CNTs bundles surrounding $\mathrm{Al}_{2} \mathrm{O}_{3}$ grains. Taking into account the morphological parameter obtained for CNT agglomerates (Table 1), it is concluded that CNTs are well distributed throughout the $\mathrm{Al}_{2} \mathrm{O}_{3}$ matrix since the surface density of SWCNTs agglomerates value is very low $\left(\rho_{\mathrm{s}} \sim 0.3 \%\right)$. SWCNTS agglomerates and the empty space associated to them contribute to this surface density value. The porosity of the nanocomposites is about $0.4 \%$ since their relative density is $99.6 \%$. Then a rough comparison between the surface density and porosity values indicates that a low fraction of SWCNTs are forming agglomerates and most of them are well distributed throughout the $\mathrm{Al}_{2} \mathrm{O}_{3}$ matrix. It is worth emphasizing that the addition of CNTS improves the densification of the material, since higher relative density values are obtained for nanocomposites (99.6\%) compared to pure $\mathrm{Al}_{2} \mathrm{O}_{3}$ (99.1\%). This fact should be correlated to the grain growth inhibition effect. Thus, CNTs impede $\mathrm{Al}_{2} \mathrm{O}_{3}$ grain growth and consequently the generation of cavities and porosity associated to this grain growth.

In order to check the CNTs integrity, Raman spectroscopy were performed in samples after sintering and testing. Figure 2 shows the Raman spectra carried out in the SWCNT- $\mathrm{Al}_{2} \mathrm{O}_{3}$ nanocomposites after sintering and testing. Raman spectra measured in $\mathrm{Al}_{2} \mathrm{O}_{3}$ and SWCNTs are included for the sake of comparison. Figure 2.a displays the typical G mode $(\sim 1550-1600$ $\mathrm{cm}^{-1}$ ) corresponding to the tangential shear mode of carbon atoms. An unsymmetrical G mode is characteristic of SWCNTs whereas a symmetric G mode at $1580 \mathrm{~cm}^{-1}$ is typical of graphite. 
G mode in composites displays a slightly higher Raman shift than in SWCNT which can be attributed to residual stresses undergoes by SWCNTs in the ceramic matrix. D-band at 1350 $\mathrm{cm}^{-1}$, which is a band activated by defects in carbon materials and then characteristic of graphite, is not perceptible in our starting SWCNTs. This attests the high quality of the carbon nanotubes used in this work. Although this $\mathrm{D}$ band is observed in SWCNT- $\mathrm{Al}_{2} \mathrm{O}_{3}$ nanocomposites after sintering and testing, the low $\mathrm{I}_{\mathrm{D}} / \mathrm{I}_{\mathrm{G}}$ ratio indicates the absence of severe damages in the CNTs structure. Peaks at 378, 416, 430, 576, 644 and $750 \mathrm{~cm}^{-1}$ corresponding to the Raman bands for $\mathrm{Al}_{2} \mathrm{O}_{3}[35]$ are also observed in the Raman spectra of both as sintered SWCNT- $\mathrm{Al}_{2} \mathrm{O}_{3}$ nanocomposites and after creep test (Figure $2 \mathrm{~b}$ ).

Figure 3 shows the creep curves for pure $\mathrm{Al}_{2} \mathrm{O}_{3}$ and $\mathrm{SWCNT}-\mathrm{Al}_{2} \mathrm{O}_{3}$ nanocomposites, where it is observed that the steady-state strain rate is reached at all stress and temperature conditions during the creep. This indicates that microstructure of both samples does not evolve during the creep tests. Although Table 1 shows a slight grain growth for $\mathrm{Al}_{2} \mathrm{O}_{3}$, it should take place at the beginning of the creep test and afterwards the microstructure should keep stable during the test. That would also explain that the first transient state of the creep test is slightly longer compared to the next ones. It is remarkable the small difference in the steady-state strain rates of both samples submitted under similar conditions. Thus, at $1250^{\circ} \mathrm{C}$ and under a stress of $36 \mathrm{MPa}$, the steady-state strain rate is $1.7 \cdot 10^{-7} \mathrm{~s}^{-1}$ and $\sim 5 \cdot 10^{-7} \mathrm{~s}^{-1}$ for $\mathrm{Al}_{2} \mathrm{O}_{3}$ and SWCNT- $\mathrm{Al}_{2} \mathrm{O}_{3}$ nanocomposites respectively. At this point it is worth emphasizing that samples exhibit different grain size and strain rates cannot be directly compared. Then, using Equation (1), taking a grain size exponent $p=2[26]$ and normalizing to a grain size of $0.5 \mu \mathrm{m}$, the steadystate strain rates become much closer $4.3 \cdot 10^{-7} \mathrm{~s}^{-1}$ and $3.4 \cdot 10^{-7} \mathrm{~s}^{-1}$ for $\mathrm{Al}_{2} \mathrm{O}_{3}$ and $\mathrm{SWCNT}-\mathrm{Al}_{2} \mathrm{O}_{3}$ nanocomposites respectively. Figure 4 shows the strain rate vs stress plot for $\mathrm{Al}_{2} \mathrm{O}_{3}$ and SWCNT- $\mathrm{Al}_{2} \mathrm{O}_{3}$ nanocomposites where all data have been normalized to a grain size of $0.5 \mu \mathrm{m}$ and using a grain size exponent $p=2 . \quad \mathrm{Al}_{2} \mathrm{O}_{3}$ exhibits a stress exponent $\mathrm{n}$ of 1.3-1.5 and for 
SWCNT- $\mathrm{Al}_{2} \mathrm{O}_{3}$ nanocomposites it increases slightly to $n$ equal to 1.6-1.8. This small difference could be related to a higher stress range applied to $\mathrm{Al}_{2} \mathrm{O}_{3}$. These values for the stress exponent $n$ along with no grain evolution during the creep tests are pointing out GBS as the deformation mechanism. Figure 5 shows the activation energy Q obtained from our experiments. A similar value of about $\mathrm{Q} \sim 780 \mathrm{~kJ} / \mathrm{mol}$ is obtained for both $\mathrm{Al}_{2} \mathrm{O}_{3}$ and $\mathrm{SWCNT}-\mathrm{Al}_{2} \mathrm{O}_{3}$ nanocomposites. This value is in good agreement with the activation energy $Q=800 \mathrm{~kJ} / \mathrm{mol}$ for oxygen diffusion in the lattice as it was suggested by Ruano et al.[26]. However, due to the high dispersion in the diffusion coefficient and the activation energy values [31] it is not clear which one is the slower specie, aluminium or oxygen, moving through the lattice. Beside this controversy, it is worth emphasizing that GBS seems to be accommodated by lattice diffusion leaving the role of grain boundaries diffusion in a second place. Then, now it is well understood that the presence of CNTs has not a perceivable effect on the mechanical properties. From these results, it would be very interesting to check the possible influence of the processing routine (and consequently the CNTs dispersion) or the type of CNTs on the $\mathrm{Al}_{2} \mathrm{O}_{3}$ plasticity as it was investigated for 3YTZP-ceramics [18,36].

In this work, we have obtained similar activation energy $\mathrm{Q}$ and stress exponent $n$ values for both $\mathrm{Al}_{2} \mathrm{O}_{3}$ and $\mathrm{SWCNT}-\mathrm{Al}_{2} \mathrm{O}_{3}$ nanocomposites, and then a similar high temperature mechanical behaviour. This fact contrast to some results reported by other authors where a great enhancement of about two order of magnitude in the creep resistant of $\mathrm{Al}_{2} \mathrm{O}_{3}$ due to the addition of CNTs was discussed [19]. However, in their work only SWCNT- $\mathrm{Al}_{2} \mathrm{O}_{3}$ nanocomposites were fabricated and the obtained mechanical results were compared with creep data for pure alumina from the literature. The fact is that there exists an extensive variety of alumina creep data depending on the microstructure and in particular on the alumina purity [26] since the diffusion kinetics processes are very sensitive to the presence of impurities [31]. For instance, Ti-doping decreases and Mg-doping increases the oxygen lattice diffusion and 
consequently that would affect the strain rate. To avoid this problem and be able to stablish reliable comparisons, both $\mathrm{Al}_{2} \mathrm{O}_{3}$ and SWCNT- $\mathrm{Al}_{2} \mathrm{O}_{3}$ nanocomposites were fabricated under identical conditions and the experimental results have led to a similar creep behavior.

\section{Conclusions}

High temperature mechanical behaviour of alumina and alumina/SWCNT nanocomposites has been studied in this work. Samples exhibit a very similar mechanical behaviour. Thus, in the temperature and stress range of our experiments, the addition of SWCNTs in $\mathrm{Al}_{2} \mathrm{O}_{3}$ matrix has a negligible effect on the high temperature mechanical properties. In both cases, GBS accommodated by lattice diffusion (Nabarro-Herring type) has been identified as the deformation mechanism. Then, the predominant role of the bulk compared with grain boundaries could explain the negligible influence of the presence of CNTs at the grain boundaries on the plasticity of these nanocomposites. Hence, both alumina and alumina/SWCNT nanocomposites behave similarly.

\section{Acknowledgements}

This work was financially supported by the European Regional Development Fund and the Spanish "Ministerio de Economía y Competitividad" through the projects MAT2009-11078, MAT2012-34217 and the project from the Andalucia Government P12-FQM-1079. M. C-R thanks the JAE-doc contract awarded by the Spanish CSIC, co-financed by the European Social Fund. 


\section{References}

[1] R. G. Munro, Evaluated material properties for a sintered alumina, J. Am. Ceram. Soc. 80 (1997) 1919-1928

[2] A. Krell, P. Blank, L.M. Berger, V. Richter, Alumina tools for machining chilled cast iron, hardened steel. Am. Ceram. Soc. Bull. 78 (1999) 65-73.

[3] E. Medvedovski. Alumina-mullite ceramics for structural applications, Ceram. Int. 32 (2006) 369-375.

[4] H. Ohnabe, S. Masaki, M. Onozuka, K. Miyahara, T. Sasa, Potential application of ceramic matrix composites to aero-engine components. Composites, A: Appl. Sci. Manuf. 30 (1999) 489-496.

[5] B.R. Lawn, Fracture of brittle solids, second ed., Cambridge University Press, Cambridge 1990.

[6] M.M. J. Treacy, T.W. Ebbesen, J.M. Gibson, Exceptionally High Young's Modulus Observed for Individual Carbon Nanotubes, Nat. 381 (1996) 678-680.

[7] A. Thess, R. Lee, P. Nikolaev, H. Dai, P. Petit, J. Robert, Crystalline Ropes of Metallic Carbon Nanotubes, Sci. 273 (1996) 483-487.

[8] R.H. Baughman, A.A. Zakhidov, W.A. de Heer, Carbon Nanotube-the Route Toward Applications, Sci. 297 (2000) 787-792.

[9] N.P. Padture, W.A. Curtin, Comment on Effect of Sintering Temperature on a Single-Wall Carbon Nanotube-Toughened Alumina Based Composite, Scr. Mater. 58 (2008) 989-990.

[10] N.P.Padture, Multifunctional Composites of Ceramics and Single-Walled Carbon Nanotubes, Adv. Mater. 21 (2009) 1767-1770. 
[11] G.D. Zhan, J.D. Kuntz, J. Wan, A.K. Mukherjee, Single Wall Carbon Nanotubes as Attractive Toughening Agents in Alumina-Based Nanocomposites, Nat. Mater. 2 (2003) 3842.

[12] X. Wan, N.P. Padture, H. Tanaka, Contact-Damage-Resistant Ceramic/Single-Wall Carbon Nanotubes and Ceramic/Graphite Composites, Nat. Mater. 3 (2004) 539-544.

[13] J. Sun, L. Gao, M. Iwasa, T. Nakayama, K. Niihara, Failure investigation of carbon nanotube/3YTZP nanocomposites, Ceram. Int. 31 (2005) 1131-1134.

[14]. R. Poyato, A. Gallardo-López, F. Gutierrez-Mora, A. Morales-Rodríguez, A. Muñoz, A. Domínguez-Rodríguez, Effect of High SWNT Content on the Room Temperature Mechanical Properties of Fully Dense 3YTZP/SWNT Composites, J. Eur. Ceram. 34 (2014) 1571-1579.

[15]. E. Zapata-Solvas, D. Gómez-García, A. Domínguez-Rodríguez, Towards Physical Properties Tailoring of Carbon Nanotubes-Reinforced Ceramic Matrix Composites, J. Eur. Ceram. Soc. 32 (2012) 3001-3020.

[16] M.H. Bocanegra-Bernal, C. Domínguez-Rios, J. Echebarria, A. Reyes-Rojas, A. GarcíaReyes, A. Aguilar-Elguezabal, Spark plasma sintering of multi-, single/doble- and singlewallet carbon nanotube-reinforced alumina composites: Is it justifiable the effort to reinforce them?, Ceram. Inter. 42 (2016), 2054-62.

[17] M. Mazaheri, D. Mari, R. Hesabi, R. Schaller, G. Fantozzi, Multi-Walled Carbon Nanotube/Nanostructured Zirconia Composites: Oustanding Mechanical Properties in a Wide Range of Temperature, Comp. Sci. Technol. 71 (2011) 939-945.

[18] M. Castillo-Rodríguez, A. Muñoz, A. Morales-Rodríguez, R. Poyato, A. Gallardo-López, A. Domínguez-Rodríguez, Influence of the processing route on the carbon nanotubes 
dispersion and creep resistance of 3YTZP/SWCNTs nanocomposites, J. Am. Ceram. Soc. 98 (2015) 645-653.

[19] E. Zapata-Solvas, R. Poyato, D. Gómez-García, A. Domínguez-Rodríguez, V. Radmilovic, N. P. Padture, Creep-Resistant Composites of Alumina and Single-Wall Carbon Nanotubes, Appl. Phys. Lett. 92 (2008) 111912-14.

[20] E. Zapata-Solvas, D. Gómez-García, R. Poyato, Z. Lee, M. Castillo-Rodríguez, A. Dominguez-Rodríguez, V. Radmilovic, N. Padture., Microstructural Effects on the Creep Deformation of Alumina/Single-Wall Carbon Nanotubes Composites, J. Am. Ceram. Soc. 93 (2010), 2042-47.

[21] E. Zapata-Solvas, D. Gómez-García, A. Domínguez-Rodríguez "Towards physical properties tailoring of carbon nanotubes-reinforced ceramic matrix composites" J. Eur. Ceram. Soc. 32 (2012) 3001-3020

[22] M. Estili, Y. Sakka, W.W. Wu, T. Nishimura, H. Yoshida, A. Kawasaki, Perfect HighTemperature Plasticity Realized in Multiwalled Carbon Nanotube-Concentrated $\alpha-\mathrm{Al}_{2} \mathrm{O}_{3}$ Hybrid, J. Am. Ceram. Soc. 96 (2013) 1904-1908.

[23] Q. Huang, Y.S. Bando, X.Xu, T. Nishimura, C.Y. Zhi, C. Tang, F. Xu, L. Gao, D. Golberg, Enhancing Superplasticity of Engineering Ceramics by Introducing BN Nanotubes, Nanotechnol. 18 (2007) 485706-12.

[24] R.M. Cannon, R. L. Coble, Deformation ceramic materials, Plenum Press, New York 1975 .

[25] A.H. Chokshi, J. R. Porter, High temperature mechanical properties of single phase alumina, J. Mater. Sci. 21 (1986) 705-710. 
[26] O. A. Ruano, J. Wadsworth, O.D. Sherby, Deformation of fine grained alumina by grain boundary sliding accommodated by slip, Acta Mater. 51 (2003) 3617-3634.

[27] R.M. Cannon, W.H. Rhodes, A. H. Heuer, Plastic deformation of fine-grained alumina $\left(\mathrm{Al}_{2} \mathrm{O}_{3}\right) ;$ I, Interface-controlled diffusional creep, J. Am. Ceram. Soc. 63 (1980) 46-53.

[28] J.D. Wang, R. Raj, Interface effects in superplastic deformation of alumina containing zirconia, titania or hafnia as a second phase, Acta Metall. Mater. 39 (1991) 2909-2919.

[29] P.A. Lessing, R.S. Gordon, Creep of Polycrystalline Alumina, Pure and Doped with Transition Metal Impurities, J. Mater. Sci. 12 (1977) 2291-2302

[30] A. Domínguez-Rodríguez, D. Gómez-García, F. Wakai, High Temperature Plasticity in Yttria Stabilised Tetragonal Zirconia Polycrystals (Y-TZP), Int. Mater. Rev. 58 (2013) 399417.

[31] A.H. Heuer, Oxygen and Aluminium Diffusion in $\alpha-\mathrm{Al}_{2} \mathrm{O}_{3}$ : How much do we really understand?, J. Eur. Ceram. 28 (2008) 1495-1507.

[32] M. Castillo-Rodríguez, A. Muñoz, A. Domínguez-Rodríguez, Correlation Between Microstructure and Creep Behavior in Liquid-Phase-Sintered $\alpha$-Silicon Carbide, J. Am. Ceram. Soc. 89 (2006) 960-967.

[33] A. Datye, K.H. Wu, G. Gomes, V. Monroy, H.T. Lin, J. Vleugels, K. Vanmeensel, Synthesis, Microstructure and Mechanical Properties of Yttria Stabilized Zirconia (3YTZP) Multi-Walled Nanotube (MWNTs) Nanocomposite by Direct in-situ Growth of MWNTs on Zirconia Particles, Comp. Sci. Technol. 70 (2010) 2086-2092.

[34] A. Duszová, J. Dusza, K. Tomasek, G. Blugan, J. Kuebler, Microstructure and properties of Carbon Nanotube/Zirconia Composite, J. Eur. Ceram. Soc. 28 (2008) 1023-1027. 
[35] A. Rincón, R. Moreno, A.S.A. Chinelatto, C.F. Gutierrez, E. Rayón, M.D. Salvador, A. Borrell, $\mathrm{Al}_{2} \mathrm{O}_{3}-3$ YTZP-Graphene Multilayers Produced by Tape Casting and Spark Plasma Sintering, J. Eur. Ceram. Soc. 34 (2014) 2427-2434.

[36] M. Castillo-Rodríguez, A. Muñoz, A. Domínguez-Rodríguez, Comparative study on high temperature mechanical behaviour in 3YTZP containing SWCNTs or MWCNTs, J. Eur. Ceram. Soc. 36 (2016) 2573-2578. 


\section{FIGURE CAPTIONS}

Fig. 1. HRSEM micrographs of $\mathrm{Al}_{2} \mathrm{O}_{3}$ (a) and $\mathrm{SWCNT}-\mathrm{Al}_{2} \mathrm{O}_{3}$ nanocomposites (c) prior creep tests. After testing, the microstructure of $\mathrm{Al}_{2} \mathrm{O}_{3}$ and $\mathrm{SWCNT}-\mathrm{Al}_{2} \mathrm{O}_{3}$ nanocomposites is shown in (b) and (d) respectively. (e) Fracture surface micrograph at higher magnification of a creep tested SWCNT- $\mathrm{Al}_{2} \mathrm{O}_{3}$ nanocomposites showing CNTs bundles located on the $\mathrm{Al}_{2} \mathrm{O}_{3}$ grain boundaries.

Fig. 2. (a) Raman spectra of $\mathrm{Al}_{2} \mathrm{O}_{3}$, SWCNTs and $\mathrm{SWCNT}-\mathrm{Al}_{2} \mathrm{O}_{3}$ nanocomposites before and after creep tests. (b) Raman spectra of the samples where theoretical peaks for $\mathrm{Al}_{2} \mathrm{O}_{3}$ are also indicated.

Fig. 3. Creep curves for a) $\mathrm{Al}_{2} \mathrm{O}_{3}$ and b) SWCNT- $\mathrm{Al}_{2} \mathrm{O}_{3}$ nanocomposites. Temperature and stress values are indicated for every steady-state as well as the stress exponent $\mathrm{n}$ and the activation energy Q.

Fig. 4. Strain rate-stress logarithm plot for $\mathrm{Al}_{2} \mathrm{O}_{3}$ and $\mathrm{SWCNT}-\mathrm{Al}_{2} \mathrm{O}_{3}$ nanocomposites displaying the average stress exponent $\mathrm{n}$ for each test temperature. Data were normalized to a grain size of $\mathrm{d}=0.5 \mu \mathrm{m}$ and using a grain size exponent $p=2$.

Fig. 5. Strain rate in logarithmic scale versus $1 / \mathrm{T}$ plot for $\mathrm{Al}_{2} \mathrm{O}_{3}$ and $\mathrm{SWCNT}-\mathrm{Al}_{2} \mathrm{O}_{3}$ nanocomposites, where data were normalized to $\sigma=100 \mathrm{MPa}$. Solid trend lines in black and grey correspond to $\mathrm{Al}_{2} \mathrm{O}_{3}$ and $\mathrm{SWCNT}-\mathrm{Al}_{2} \mathrm{O}_{3}$ nanocomposites respectively. Dashed trend lines for data normalized to $\mathrm{d}=0.5 \mu \mathrm{m}$ are also included. As shown, a similar activation energy value $\mathrm{Q}$ is obtained in both cases, and a practically identical strain rate after normalization to $\mathrm{d}=0.5$ $\mu \mathrm{m}$. 


\section{TABLES}

Table I. Relative density $\rho_{\mathrm{r}}$ and morphological parameters (grain size $d$ and shape factor $F$ ) for $\mathrm{Al}_{2} \mathrm{O}_{3}$ and SWCNT- $\mathrm{Al}_{2} \mathrm{O}_{3}$ nanocomposites, as-sintered and after creep tests.

\begin{tabular}{|c|c|c|c|c|c|c|}
\hline \multirow{2}{*}{ Material } & \multirow{2}{*}{$\begin{array}{c}\rho_{r} \pm 0.5 \\
(\%)\end{array}$} & \multicolumn{2}{|c|}{$\mathrm{Al}_{2} \mathrm{O}_{3}$ grains } & \multicolumn{3}{|c|}{ SWCNTs agglomerates } \\
\hline & & $d(\mu \mathrm{m})$ & $\boldsymbol{F}$ & $\rho_{s}(\%)$ & $d(\mu \mathbf{m})$ & $\boldsymbol{F}$ \\
\hline $\mathrm{Al}_{2} \mathrm{O}_{3}$ & \multirow{2}{*}{99.1} & $0.63 \pm 0.42$ & $0.64 \pm 0.10$ & & & \\
\hline $\mathrm{Al}_{2} \mathrm{O}_{3}$ deformed & & $0.78 \pm 0.48$ & $0.60 \pm 0.11$ & & & \\
\hline $\mathrm{Al}_{2} \mathrm{O}_{3} / \mathrm{SWCNTs}$ & \multirow{2}{*}{99.6} & $0.36 \pm 0.17$ & $0.65 \pm 0.09$ & \multirow{2}{*}{$0.27 \pm 0.03$} & \multirow{2}{*}{$0.4 \pm 0.4$} & \multirow{2}{*}{$0.80 \pm 0.15$} \\
\hline $\begin{array}{c}\mathrm{Al}_{2} \mathrm{O}_{3} / \mathrm{SWCNTs} \\
\text { deformed }\end{array}$ & & $0.36 \pm 0.23$ & $0.61 \pm 0.12$ & & & \\
\hline
\end{tabular}




\section{(a)}

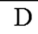

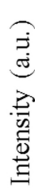

$\mathrm{Al}_{2} \mathrm{O}_{3} / \mathrm{SWCNTs}$ deformed

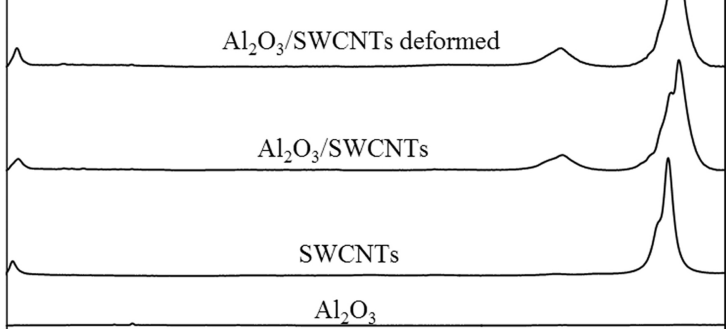

150

650

1150

Raman shift $\left(\mathrm{cm}^{-1}\right)$

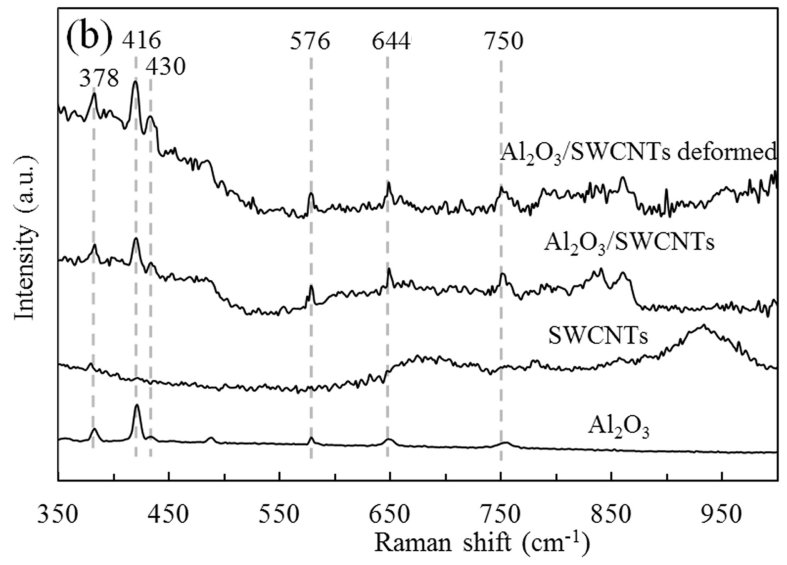




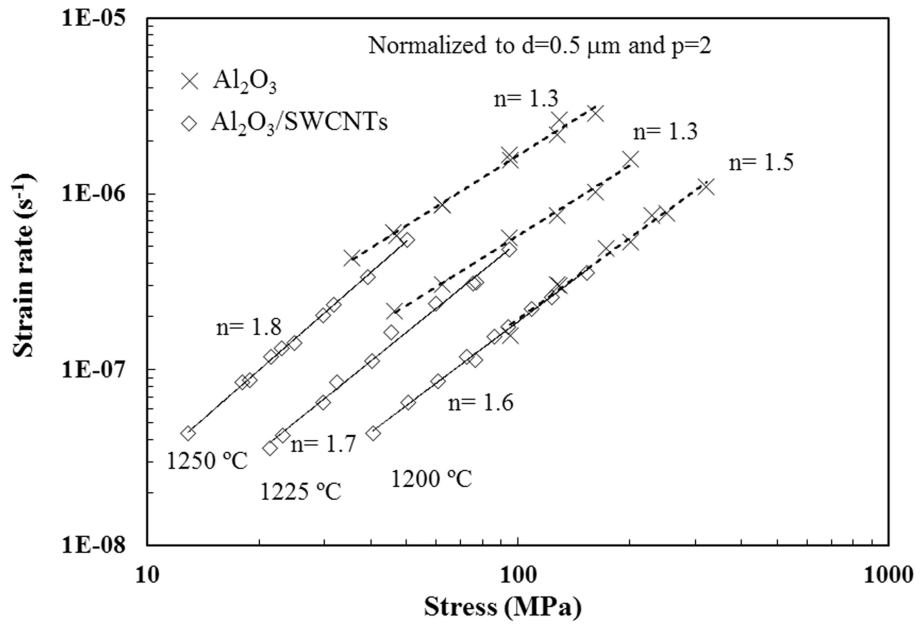


